\title{
USING THE DEMATEL MODEL FOR THE FMEA RISK ANALYSIS
}

doi: $\quad 10.2478 /$ czoto-2019-0070

Date of submission of the article to the Editor: $27 / 11 / 2018$

Date of acceptance of the article by the Editor: 16/01/2018

\author{
Marián Bujna ${ }^{1}$ - orcid id: 0000-0003-4281-5649 \\ Martin Kotus ${ }^{2}$ - orcid id: 0000-0002-0630-8132 \\ Eva Matušeková ${ }^{3}$ - orcid id: 0000-0002-0528-3519 \\ ${ }^{1}$ Slovak University of Agriculture, Slovak Republic \\ ${ }^{2}$ Slovak University of Agriculture, Slovak Republic martin.kotus@uniag.sk \\ ${ }^{3}$ Slovak University of Agriculture, Slovak Republic
}

\begin{abstract}
Technological progress has brought a large amount of complex machinery into the work processes, which represents a potential source of serious injuries, accidents, or breakdowns. The aim of this paper is to follow new trends in the FMEA and their use in our study. We have chosen the Turning Machine Doosan V-Puma Doosan PUMA V550R Machining Centre with manufacturing diameters and mechanical machining operations. We have created the FMEA team, which participated in the entire evaluation and analysis. We identified possible failures and causes of failures in the given operations. We applied the conventional PFMEA and identified the RPN risk number. We also used DEMATEL model. Using DEMATEL matrices, we identified a binding between the individual failures and the causes of the failures. Some failures will become the main cause of other failures and the causes of the failures; some arise as a result of other failures or causes of failures. Finally, we evaluated the applicability of individual methods and models. By the DEMATEL model we clarified the significance and bindings between individual failures.
\end{abstract}

Keywords: safety, risk management, work process, quality production

\section{INTRODUCTION}

A risk assessment is not only an important step in ensuring a safe and healthy work environment, it is a legal requirement. It needs to be conducted before employee's complete work on current, new or unknown parts, processes or materials. We must consider the possible causes of harm and what steps to take in preventing the harm in the first place. If our business has fewer than 5 employees, you don't have to document anything, but you must have considered hazards and control measures (Korenko et al., 2015; Prístavka et al., 2014; Tureková, 2016; Knop et al., 2018)

Failure Modes and Effects Analysis (FMEA) is methodology for analyzing potential reliability problems early in the development cycle where it is easier to take actions to overcome these issues, thereby enhancing reliability through design. FMEA is used to 
identify potential failure modes, determine their effect on the operation of the product, and identify actions to mitigate the failures. A crucial step is anticipating what might go wrong with a product. While anticipating every failure mode is not possible, the development team should formulate as extensive a list of potential failure modes as possible (Bujna and Beloev, 2015; Girmanová et al., 2017; Žitňák et al., 2014)

DEMATEL ((Decision-Making Trial and Evaluation Laboratory) clarifies the complex relationships between factors and provides solutions by com- paring these factors in the system, using matrix operations to calculate the direct and indirect causal relationships and extent of influence, and quantifying the extent of mutual influence between factors (Tsai S-B. et al., 2017).

\section{METHODOLOGY OF RESEARCH}

In the monograph, we focused on the risk analysis of the Doosan PUMA V550R lathe. Applying the conventional FMEA process method:

1. Review the process

2. Brainstorm potential failure modes

3. List potential effects of each failure

4. Assign Severity, Occurrence and Detection rankings (tab.1)

5. Calculate the RPN $=$ Severity $\times$ Occurrence $\times$ Detection

6. Take action

Table 1

Rating of severity, occurrence and detection

\begin{tabular}{|c|l|r|r|l|}
\hline No. & \multicolumn{1}{|c|}{ Aspect } & $\mathbf{1}$ & $\begin{array}{c}\text { Rating Values } \\
----->>\end{array}$ & 10 \\
\hline 1. & Severity & insignificant & $------>$ & catastrophic \\
\hline 2. & Occurrence & extremely unlikely & $------->$ & inevitable \\
\hline 3. & Detection & absolutely certain to detect & $------>>$ & no control exists \\
\hline
\end{tabular}

Source: (Nguyen et al., 2016)

The calculation procedures of DEMATEL can be summarized into the following steps (Tsai et al., 2017; Chen et al., 2016; Deng et al., 2014; Luthra et al., 2016;):

1. Establishing the measurement scale and determining the causal relationships List and define the various factors involved in a complex system through a literature review, brainstorming session, or expert survey. Design a scale to demonstrate the extent of influence of these factors and employ pair-wise comparison to elucidate the causal relationships between the factors.

2. Establishing a direct-relation matrix

$$
x=\left[\begin{array}{cccc}
0 & x_{12} & \Lambda & x_{1 n} \\
\mathrm{M} & 0 & \Lambda & \mathrm{M} \\
\mathrm{M} & \mathrm{M} & \mathrm{O} & \mathrm{M} \\
x_{n 1} & x_{n 2} & \Lambda & 0
\end{array}\right]
$$

We determine the presence and extent of influence relationships between the factors. We use the results to create a direct-relation matrix, where values in the matrix represent the extent of influence between the factors. Set the values on the diagonal line in the matrix to zero. 
3. Calculating the normalized direct-relation matrix

Use the column vectors and maximum values as the baseline for normalization.

$$
\begin{gathered}
\lambda=\frac{1}{\max _{1 \leq i \leq n} \sum_{j=1}^{n} x_{i j}} \\
N=\lambda \cdot X
\end{gathered}
$$

4. Calculating the direct/indirect-relation matrix $(\mathrm{T})$ or the total-relation matrix:

$$
T=\lim _{n \rightarrow \infty}\left(N+N^{2}+. .+N^{k}\right)=N \cdot(1-N)
$$

where I represent the identity matrix.

5. Calculating the values in each row and column

Sum the values in each row and column in the total-relation matrix $(T)$. Let $D_{i}$ be the sum of the -i-th column and $R_{j j}$ be the sum of the j-th row. Thus, the $D_{i}$ and $R_{i}$ values comprise both indirect and direct influences.

$$
\begin{aligned}
& D_{i}=\sum_{j=1}^{n} t_{i j(}(i=1,2, \ldots, n \\
& R_{i}=\sum_{j=1}^{n} t_{i j(}(i=1,2, \ldots, n
\end{aligned}
$$

6. Illustrating the DEMATEL cause-and-effect diagram

Attribute $k$ is either a cause or effect attribute when $\left(D_{k}-R_{k}\right)$ is a positive or negative value. The size of the $\left(D_{k}+R_{k}\right)$ represents the extent of the attribute's cause or effect. Based on the coordinates in $\left(D_{k}+R_{k}\right)$ and $\left(D_{k}-R_{k}\right), k$ can be categorized into four categories:

1. Positive $\left(D_{k}-R_{k}\right)$ and large $\left(D_{k}+R_{k}\right)$ values: $k$ is a cause factor and an actuating factor for solving the problem.

2. Positive $\left(D_{k}-R_{k}\right)$ and small $\left(D_{k}+R_{k}\right)$ values: $k$ is an independent factor and influences only a small number of other factors.

3. Negative $\left(D_{k}-R_{k}\right)$ and small $\left(D_{k}+R_{k}\right)$ values: $k$ is an independent factor and is influenced by only a small number of factors.

4. Negative $\left(D_{k}-R_{k}\right)$ and large $\left(D_{k}+R_{k}\right)$ values: $k$ is a core problem that requires resolution. However, it is an effect attribute, and thus it cannot be directly improved. 


\section{RESULTS}

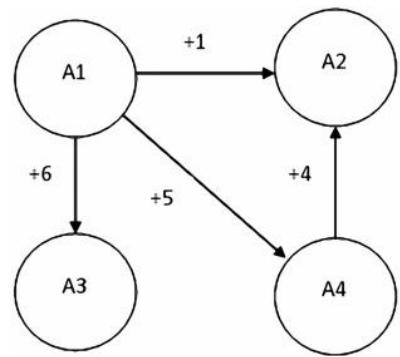

Fig. 1 Relationship by DEMATEL (Tsai et al., 2017)

During turning, in terms of turning the diameter of a given component, we identified twelve defects, where we determined the consequences and causes of these defects (tab. 2).

Table 2

PFMEA for Operation - Turning diameters

\begin{tabular}{|c|c|c|c|c|c|c|}
\hline Failure & Consequences & $\mathbf{S}$ & Causes & 0 & D & RPN \\
\hline $\begin{array}{l}\text { Outside } \\
\text { diameter is } \\
\text { below the } \\
\text { tolerance issue }\end{array}$ & $\begin{array}{l}\text { Parts are out of tolerance } \\
\text { Customer complaint }\end{array}$ & 7 & Too high feed rate & 3 & 4 & 84 \\
\hline $\begin{array}{l}\text { Outside } \\
\text { diameter is } \\
\text { above the } \\
\text { tolerance issue }\end{array}$ & $\begin{array}{l}\text { Customer complaint } \\
\text { Scrap } \\
\text { Unmountable parts } \\
\text { Termination of contract due } \\
\text { to frequent complaints }\end{array}$ & 9 & Too low feed rate & 3 & 4 & 108 \\
\hline $\begin{array}{l}\text { Inside diameter } \\
\text { is below } \\
\text { tolerance }\end{array}$ & $\begin{array}{l}\text { Customer complaint } \\
\text { Waste } \\
\text { Unmountable parts } \\
\text { Termination of contract due } \\
\text { to frequent complaints }\end{array}$ & 9 & Cutting blade is worn out & 7 & 2 & 126 \\
\hline $\begin{array}{l}\text { Inside diameter } \\
\text { is above } \\
\text { tolerance }\end{array}$ & $\begin{array}{l}\text { Customer complaint } \\
\text { Parts are outside } \\
\text { specification }\end{array}$ & 7 & $\begin{array}{l}\text { Incorrectly chosen } \\
\text { measurement method or } \\
\text { measurement device }\end{array}$ & 3 & 2 & 42 \\
\hline $\begin{array}{l}\text { Pitch diameter is } \\
\text { below tolerance }\end{array}$ & $\begin{array}{l}\text { Customer complaint } \\
\text { Parts are outside } \\
\text { specification }\end{array}$ & 7 & Infeed turned off late & 3 & 5 & 105 \\
\hline $\begin{array}{l}\text { Thickness of the } \\
\text { pitch is above } \\
\text { the tolerance }\end{array}$ & $\begin{array}{l}\text { Customer complaint } \\
\text { Parts are outside } \\
\text { specification }\end{array}$ & 7 & Cutting blade is worn out & 5 & 2 & 70 \\
\hline $\begin{array}{l}\text { Chamfer of the } \\
\text { piston ring } \\
\text { ID/OD }\end{array}$ & Rework & 4 & $\begin{array}{l}\text { The use of manual } \\
\text { chamfering }\end{array}$ & 2 & 6 & 36 \\
\hline $\begin{array}{l}\text { Concentricity is } \\
\text { too high }\end{array}$ & $\begin{array}{l}\text { Customer complaint } \\
\text { Parts outside specification }\end{array}$ & 6 & $\begin{array}{l}\text { Incorrect measurement } \\
\text { methodology }\end{array}$ & 4 & 2 & 24 \\
\hline $\begin{array}{l}\text { Pitch radius is } \\
\text { too large }\end{array}$ & $\begin{array}{l}\text { Customer complaint } \\
\text { Parts are outside } \\
\text { specification }\end{array}$ & 7 & $\begin{array}{l}\text { Incorrectly selected } \\
\text { cutting blade }\end{array}$ & 2 & 1 & 14 \\
\hline $\begin{array}{l}\text { Incorrect } \\
\text { chamfer width }\end{array}$ & $\begin{array}{l}\text { Customer complaint } \\
\text { Parts are outside } \\
\text { specification }\end{array}$ & 7 & Incorrectly set infeed & 5 & 5 & 175 \\
\hline $\begin{array}{l}\text { Roughness } \\
\text { height }\end{array}$ & $\begin{array}{l}\text { Customer complaint } \\
\text { Parts are outside } \\
\text { specification }\end{array}$ & 7 & Feed too high & 3 & 4 & 84 \\
\hline $\begin{array}{l}\text { Unturned outer } \\
\text { diameter }\end{array}$ & Rework & 4 & Skipped operation & 2 & 2 & 16 \\
\hline
\end{tabular}


Suggested actions for failures:

1., 2., 5., 9., 10., 11. Set according to the cover sheet

3. Replace worn out cutting blade. Replace supplier

4. Choose the right measurement method and measuring device

6. Replace worn out cutting blade

7. Complete a cover sheet

8. Continuous measurement of units

12. Retrain staff

Table 4

Initial direct-relation matrix $X$ for operation 1

\begin{tabular}{|c|c|c|c|c|c|c|c|c|c|c|c|c|}
\hline Index X & I & II & III & IV & $\mathbf{V}$ & VI & VII & VIII & $\mathbf{I X}$ & $\mathbf{X}$ & $\mathbf{X I}$ & $\mathbf{X I I}$ \\
\hline $\mathbf{I}$ & 0 & 0 & 4.5 & 0 & 1.8 & 4.5 & 0 & 1.8 & 0 & 5 & 5.4 & 0 \\
\hline $\mathbf{I I}$ & 0 & 0 & 1.5 & 0 & 0 & 1.5 & 1 & 1.8 & 0 & 5 & 0 & 0 \\
\hline $\mathbf{I I I}$ & 4.2 & 1.8 & 0 & 2 & 0 & 5.4 & 4.2 & 2 & 4 & 1 & 1.8 & 0 \\
\hline $\mathbf{I V}$ & 0.6 & 0.6 & 3.5 & 0 & 0 & 3.5 & 4.2 & 5.4 & 4.2 & 4.5 & 0.6 & 2.1 \\
\hline $\mathbf{V}$ & 4.2 & 0 & 3.1 & 0 & 0 & 0.7 & 1.2 & 3.6 & 2.7 & 3.5 & 4.2 & 0 \\
\hline $\mathbf{V I}$ & 4.2 & 1.8 & 5.4 & 2 & 0 & 0 & 4.2 & 2 & 4 & 1 & 2.5 & 0 \\
\hline VII & 1.9 & 0.7 & 0 & 0 & 1.3 & 0 & 0 & 0 & 0 & 0.3 & 1.9 & 1.7 \\
\hline VIII & 0.6 & 0.6 & 3.5 & 4 & 0 & 3.5 & 4.2 & 0 & 4.2 & 4.5 & 0.6 & 0 \\
\hline $\mathbf{I X}$ & 4.8 & 2.3 & 3.1 & 5.2 & 0 & 5.8 & 3.2 & 5.2 & 0 & 3 & 4.8 & 0 \\
\hline $\mathbf{X}$ & 3 & 3 & 3.7 & 0 & 1.9 & 4.5 & 0 & 1.9 & 0 & 0 & 3 & 0 \\
\hline $\mathbf{X I}$ & 5.4 & 0 & 4.5 & 0 & 1.8 & 4.5 & 0 & 1.8 & 0 & 5 & 0 & 0 \\
\hline $\mathbf{X I I}$ & 0 & 0 & 0 & 5.2 & 0 & 0 & 0.2 & 4.8 & 0 & 0 & 0 & 0 \\
\hline
\end{tabular}

Table 5

Use the column vectors and maximum values as the baseline for normalization

\begin{tabular}{|c|c|c|c|c|c|c|c|c|c|c|c|c|}
\hline$\sum x i(1)$ & 23 & 10.8 & 26.4 & 29.2 & 23.2 & 27.1 & 7.8 & 25.7 & 37.4 & 21 & 23 & 10.2 \\
\hline$\sum x i j$ & \multicolumn{12}{|c|}{37.4} \\
\hline$\lambda(2)$ & \multicolumn{12}{|c|}{0.026738} \\
\hline
\end{tabular}

Example for the first row and the third column:

$$
N=\lambda \cdot X=0.027 \cdot 4,5 \cong 0.12
$$

Table 6

Normalized direct-relation matrix $\mathrm{N}$

\begin{tabular}{|c|c|c|c|c|c|c|c|c|c|c|c|c|}
\hline Index N (3) & $\mathbf{I}$ & $\mathbf{I I}$ & $\mathbf{I I}$ & $\mathbf{I V}$ & $\mathbf{V}$ & $\mathbf{V I}$ & $\mathbf{V I I}$ & $\mathbf{V I I I}$ & $\mathbf{I X}$ & $\mathbf{X}$ & $\mathbf{X I}$ & $\mathbf{X I I}$ \\
\hline $\mathbf{I}$ & 0.00 & 0.00 & 0.12 & 0.00 & 0.05 & 0.12 & 0.00 & 0.05 & 0.00 & 0.13 & 0.14 & 0.00 \\
\hline II & 0.00 & 0.00 & 0.04 & 0.00 & 0.00 & 0.04 & 0.03 & 0.05 & 0.00 & 0.13 & 0.00 & 0.00 \\
\hline III & 0.11 & 0.05 & 0.00 & 0.05 & 0.00 & 0.14 & 0.11 & 0.05 & 0.11 & 0.03 & 0.05 & 0.00 \\
\hline $\mathbf{I V}$ & 0.02 & 0.02 & 0.09 & 0.00 & 0.00 & 0.09 & 0.11 & 0.14 & 0.11 & 0.12 & 0.02 & 0.06 \\
\hline $\mathbf{V}$ & 0.11 & 0.00 & 0.08 & 0.00 & 0.00 & 0.02 & 0.03 & 0.10 & 0.07 & 0.09 & 0.11 & 0.00 \\
\hline VI & 0.11 & 0.05 & 0.14 & 0.05 & 0.00 & 0.00 & 0.11 & 0.05 & 0.11 & 0.03 & 0.07 & 0.00 \\
\hline VII & 0.05 & 0.02 & 0.00 & 0.00 & 0.03 & 0.00 & 0.00 & 0.00 & 0.00 & 0.01 & 0.05 & 0.05 \\
\hline VIII & 0.02 & 0.02 & 0.09 & 0.11 & 0.00 & 0.09 & 0.11 & 0.00 & 0.11 & 0.12 & 0.02 & 0.00 \\
\hline $\mathbf{I X}$ & 0.13 & 0.06 & 0.08 & 0.14 & 0.00 & 0.16 & 0.09 & 0.14 & 0.00 & 0.08 & 0.13 & 0.00 \\
\hline $\mathbf{X}$ & 0.08 & 0.08 & 0.10 & 0.00 & 0.05 & 0.12 & 0.00 & 0.05 & 0.00 & 0.00 & 0.08 & 0.00 \\
\hline $\mathbf{X I}$ & 0.14 & 0.00 & 0.12 & 0.00 & 0.05 & 0.12 & 0.00 & 0.05 & 0.00 & 0.13 & 0.00 & 0.00 \\
\hline $\mathbf{X I I}$ & 0.00 & 0.00 & 0.00 & 0.14 & 0.00 & 0.00 & 0.01 & 0.13 & 0.00 & 0.00 & 0.00 & 0.00 \\
\hline
\end{tabular}


Table 7

Total-relation matrix $T$

\begin{tabular}{|c|c|c|c|c|c|c|c|c|c|c|c|c|}
\hline Index T (4) & I & II & III & IV & V & VI & VII & VIII & IX & $\mathbf{X}$ & XI & XII \\
\hline I & 0.14 & 0.06 & 0.26 & 0.06 & 0.08 & 0.27 & 0.09 & 0.14 & 0.09 & 0.25 & 0.24 & 0.01 \\
\hline II & 0.06 & 0.03 & 0.10 & 0.03 & 0.02 & 0.11 & 0.07 & 0.08 & 0.04 & 0.17 & 0.05 & 0.00 \\
\hline III & 0.24 & 0.10 & 0.16 & 0.12 & 0.04 & 0.30 & 0.22 & 0.16 & 0.19 & 0.16 & 0.17 & 0.02 \\
\hline IV & 0.16 & 0.08 & 0.25 & 0.09 & 0.04 & 0.27 & 0.23 & 0.26 & 0.21 & 0.25 & 0.14 & 0.07 \\
\hline V & 0.24 & 0.05 & 0.23 & 0.06 & 0.04 & 0.18 & 0.12 & 0.19 & 0.15 & 0.22 & 0.22 & 0.01 \\
\hline VI & 0.25 & 0.10 & 0.29 & 0.12 & 0.04 & 0.18 & 0.22 & 0.16 & 0.19 & 0.17 & 0.19 & 0.02 \\
\hline VII & 0.08 & 0.03 & 0.04 & 0.02 & 0.05 & 0.04 & 0.02 & 0.03 & 0.02 & 0.05 & 0.08 & 0.05 \\
\hline VIII & 0.15 & 0.08 & 0.24 & 0.18 & 0.03 & 0.25 & 0.22 & 0.11 & 0.20 & 0.24 & 0.13 & 0.02 \\
\hline IX & 0.31 & 0.14 & 0.30 & 0.23 & 0.05 & 0.38 & 0.24 & 0.28 & 0.13 & 0.27 & 0.28 & 0.02 \\
\hline $\mathbf{X}$ & 0.19 & 0.12 & 0.22 & 0.05 & 0.08 & 0.24 & 0.09 & 0.13 & 0.08 & 0.11 & 0.17 & 0.01 \\
\hline $\mathbf{X I}$ & 0.27 & 0.06 & 0.26 & 0.06 & 0.08 & 0.27 & 0.09 & 0.14 & 0.09 & 0.25 & 0.12 & 0.01 \\
\hline $\mathbf{X I I}$ & 0.04 & 0.02 & 0.07 & 0.17 & 0.01 & 0.07 & 0.07 & 0.18 & 0.05 & 0.07 & 0.04 & 0.01 \\
\hline
\end{tabular}

Thus, the $D_{i}(5)$ and $R_{i}(6)$ values comprise both indirect and direct influences.

Table 8

Summary of the prominence and relation of the 12 indices

\begin{tabular}{cccc}
\hline $\mathbf{D}$ & $\mathbf{R}$ & $\mathbf{D p R}$ & $\mathbf{D m R}$ \\
\hline 1.69 & 2.15 & 3.84 & -0.46 \\
0.74 & 0.87 & 1.62 & -0.13 \\
1.88 & 2.43 & 4.30 & -0.55 \\
2.05 & 1.19 & 3.24 & 0.86 \\
1.72 & 0.54 & 2.26 & 1.17 \\
1.92 & 2.55 & 4.47 & -0.63 \\
0.50 & 1.67 & 2.17 & -1.16 \\
1.86 & 1.88 & 3.73 & -0.02 \\
2.64 & 1.43 & 4.06 & 1.21 \\
1.49 & 2.20 & 3.69 & -0.71 \\
1.69 & 1.82 & 3.50 & -0.13 \\
0.80 & 0.24 & 1.04 & 0.55 \\
\hline
\end{tabular}

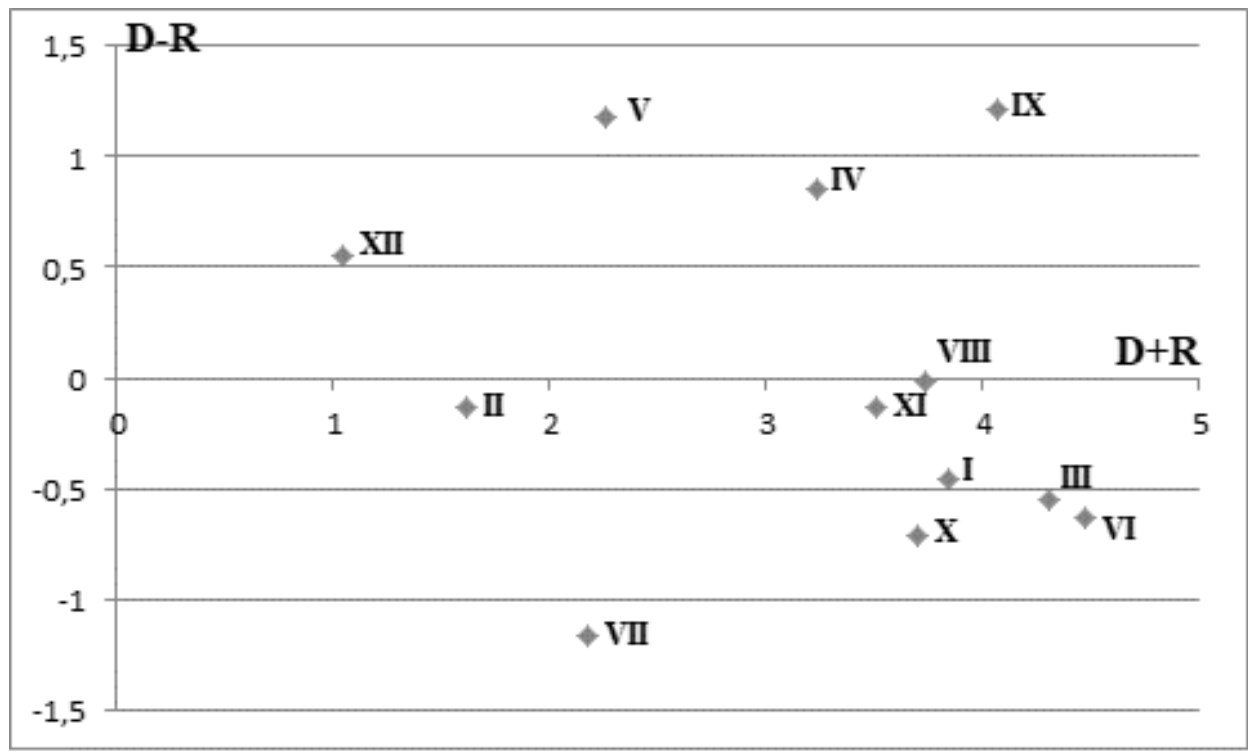

Fig. 2 Relational diagram of the 12 indices 


\section{DISCUSSION}

Failures are sorted by their bindings to other failures in the prioritization of whether they affect other failures more (they cause other failures) in proportion to how they are influenced by other failures (resulting from other failures).

The division of failures according to their significance:

1. High prominence and high relation: The indices in this quadrant comprise IV, V, IX and XII. These indices are the core cause factors influencing the other items. Thus, they are the actuating factors for solving problems.

2. Low prominence and high relation: The indices in this quadrant comprise (no failure form our study) and slightly influence a few of the other indices. Thus, they are relatively independent.

3. Low prominence and low relation: The indices in this quadrant comprise (no failure form our study) and are slightly influenced by the other indices. Thus, they are relatively independent.

4. High prominence and low relation: The indices in this quadrant comprise I, II, III, $\mathrm{VI}, \mathrm{VII}, \mathrm{VIII}, \mathrm{X}$ and $\mathrm{XI}$ and are effect factors that are influenced by the other items. Although these indices require improvement, they are effect factors, and thus they cannot be directly improved.

The dependence between RPN and the DEMATEL would be the subject of further studies.

\section{CONCLUSION}

We can use the risk analysis is to apply matrix operations to calculate factors' causal relationships and extent of influence - DEMATEL.

Reasons, why to use DEMATEL:

- for the Conventional FMEA, we identify all failure modes with a degree of severity, occurrence, and detection,

- for the Extended FMEA (wasn't the aim of this paper), we specify a particular method of costs incurred for malfunctions and their impact within the internal or external costs,

- when using DEMATEL technology, we not only identify the failure causes, but we also look at how the failure mode could be the cause of another failure,

- we monitor how malfunctions affect one another,

- we may have a problem with a relatively high RPN, but at the same time, the DEMATEL model will show us that this failure will not cause another failure, i.e., it is not the cause of another failure mode,

- we may have a problem with a relatively low RPN, but at the same time, the DEMATEL model will show us that this failure will cause a number of other failures, i.e., it is the cause of other failure modes,

- there may be other situations, but we have only described the marginal ones.

We use a model DEMATEL. DEMATEL gave us the answers to better understand the bindings between the individual failures. As part of the FMEA analysis, it is common for one failure to cause another one that actually results from its consequence, and this effect may change to the cause of another failure, etc. We use a model DEMATEL. DEMATEL gave us the answers to better understand the bindings between the individual failures. As part of the FMEA analysis, it is common for one failure to cause another one that actually results from its consequence, and this effect 
may change to the cause of another failure, etc. Why use DEMATEL? It is precisely because if we know that within the given failure we are also talking about the main cause with bindings to other failures, we can take this into account when evaluating the failure mode by FMEA. However, the direct relationship between DEMATEL and the calculated RPN or ERPN is our goal in the further studies.

\section{ACKNOWLEDGEMENTS}

The paper is related to the research project KEGA 008TU Z-4/2016 "New Forms and Methods of Education in Area of Machinery Safety".

\section{REFERENCES}

Bujna, M., Beloev, C. I. 2015. Tools of risk management in production processes. Angel Kanchev University of Ruse, Bulgaria.

Bujna, M., Dostál, P. 2017. Assessment of selected equipment by method FTA. Acta Universitatis Agriculturae et Silviculturae Mendelianae Brunensis, 65(5), 16551661.

Girmanová, L., Šolc, M., Kliment, J., Divoková, A., Mikloš, V. 2017. Application of Six Sigma Using DMAIC Methodology in the Process of Product Quality Control in Metallurgical Operation. Acta Technologica Agriculturae. 20(4). 104-109.

Guo, J.J., Tsai, S.B. 2015. "Discussing and Evaluating Green Supply Chain Suppliers: A Case Study of the Printed Circuit Board Industry in China. South African Journal of Industrial Engineering, 26 (2), pp. 56-67.

Korenko, M. et al. 2015. Risk analysis at work in manufacturing organization. Acta Universitatis Agriculturae et Silviculturae Mendelianae Brunensis, 63(5), 14931497.

Knop, K., Ingaldi, M., Smilek-Starczynowska, M. 2017. Reduction of Errors of the Conformity Assessment During the Visual Inspection of Electrical Devices. Advances in Manufacturing. Hamrol A., Ciszak O., Legutko S., Jurczyk M. (ed.) Lecture Notes in Mechanical Engineering, Springer International Publishing, Cham, 857-867.

Nguyen, T. L., Shu, M. H., Hsu, B. M. 2014. Extended FMEA for sustainable manufacturing: An empirical study in the non-woven fabrics industry. Sustainability, 8(9), 939. 2016.

Prístavka, M., Beloev, C I., Kročko, V. 2014. Quality control in production processes. Angel Kanchev University of Ruse, Bulgaria.

Rouhani, S., Ashrafi, A., Afshari, S. 2014. Fuzzy DEMATEL Model for Evaluation Criteria of Business Intelligence. Proceedings of the 16th International Conference on Enterprise Information Systems, 456-463.

Tsai, S.B., Huang, C.Y., Wang, C.K., Chen Q., et al. 2016. Using a Mixed Model to Evaluate Job Satisfaction in High-Tech Industries. Plos One, 11(5): e0154071.

Tsai, S-B, Zhou, J, Gao, Y, Wan,g J, Li G, Zheng, Y, et al. (2017) Combining FMEA with DEMATEL models to solve production process problems. Plos One 12(8): e0183634. https://doi.org/10.1371/journal.pone.0183634

Tureková, I. 2016. Evaluation of human reliability by methods of observation and coaching in the maintenance process. Proceedings from 10th International Technology, Education and Development Conference, Valencia, 752-761.

Žitñák, M., Macák, M., Korenko, M. 2014. Assessment of risks in implementing automated satellite navigation systems. Research in agricultural engineering. 60, 16-24. 